\title{
Nutritional Support
}

National Cancer Institute

\section{Source}

National Cancer Institute. Nutritional Support. NCI Thesaurus. Code C15433.

Administration of essential nutrients to a patient utilizing methods other than oral feedings. 